\title{
Economics of NHS Cost-Saving and its Morality on the 'Living Dead'
}

\author{
Emerson Abraham Jackson ${ }^{1}$
}

DOI 10.1515/JHEEC-2017-0001

\begin{abstract}
This article has been championed on account of the experience of (perceived) economic rationalization which seem to be the foremost of patients' care as opposed to addressing distress to human existing wellbeing, while in a state of being tormented with agonizing news of prolonged ill health. Several considerations have been proposed as a way of addressing the need to rationalize resources in ensuring the long standing history of the NHS focus on 'free health care' is critically covered, but not in a way that destroys confidence on the ability of professionals to manifest ethical prudence in their acts of judgments about whether patients care is to be made immediate or prolonged on a waiting list. There is certainly serious impacts to be comprehended with in situation of economic rationality through services provided by the NHS; it is believed that tangible outcomes about definitive care for patients can be addressed collaboratively.
\end{abstract}

Keywords:

JEL Classification:
Moral Economics; Cost Saving; Morality; Living Dead; NHS

D61, D64, 111

\section{Introduction}

The UK National Health Service (NHS) is one of the most highly envied of welfare state provision found in the developed economies, where the focus is geared towards servicing free health care for all. Indeed, such provision is sure to come at a high cost, particularly when the system does not discriminate against those considered to have contributed to

\footnotetext{
${ }^{1}$ Research Scholar, Centre of West African Studies, University of Birmingham. Also, a Senior Research Economist at the Bank of Sierra (Model Building and Analysis Section).
}

Disclaimer: Views expressed in this article is that of the author and do not reflect those of the institution mentioned here. 
servicing the cost of care and particularly 'free riders', who may be oblivious about how funding is sought for free health services provided to them throughout their lifetime.

One may attest to sounding the praise of such a service, despite pressure faced in attending to the effective demands of meeting patients care and welfare needs. In effect, its scope of delivery may be considered enviable when it comes to ensuring that budgetary allocation does not discriminate on the basis of social status, race and religion. In retrospect of a recent arrogant manifestation made by the President of the USA, Mr. Donald Trump, it is certainly true to know how his selfish capitalist system is set up to marginalize people on the basis of their status in society (Masters, February, 2018). On this note, it proves clearly how insensitive the US president is when it comes to understanding the plight of the needy, while his own capitalist plan is still void of a 28million budget deficit of caring for deserved citizens, who are considered (too) poor to take up private health insurance cover.

Contrary to the brilliant idea of universal free health care system, there is also critical concern of a lottery system used for prioritizing patients' needs. This actually brings one to the question of: How is the decision on a waiting list addressed for a slowly dying being determine when the psychology of (im)moral decision is already sufficient to add a death toll on the life of a hard working being? Such a question may seem ambiguous, but on deconstruction, one may also be poised to question the economics of opportunity cost here, which is geared towards immediate cost-saving as opposed to preserving lives, which may also be beneficial to reducing burden on essential services like the welfare system through overburdened costs on paying out benefits to citizens and also expenses on personalized care services like counselling.

In this article, the aim is to critically address the economics of choice for patients' care which in most cases is based on the rationalization of resources. This also throw serious ethical and moral concern around questions relating to the preservation of life and personal well-being of people. Patients' agonized feeling is quite a difficult concept to decipher by professionals, and it shows more clearly that in a given circumstance of curtailed budget to address the ill health of a patient, it is only the silent sufferer who may be faced with the pain of having to told outrightly to wait, on account of a so-called judgment by (medical) professionals about the non-urgency of a patient's specific case / illness.

\section{Historical Background of the NHS}

The National Health Service (NHS) was developed in the early years of $1948-1959$ (precisely on June 5th, 1948) in a bid to address basic (free) health care for all, irrespective of financial or other forms of status in society (Gilbert et al, 2014: 371). The system was launched by the then Health Secretary, Aneurin Bevan, at the Park Hospital in Manchester, now renamed Trafford General Hospital (NHS Choices, n/d). At the time of its inception, it was viewed as an ambitious plan and more so impossible to bring the various health care services in the UK under an umbrella of centralised governance - on a positive note, 
it seem to be serving its purpose, but very constrained in terms of meeting patients' needs. In a very practical sense, this has made it possible for medical services like in-house hospital care, medical practitioners' services, for example, doctors, nurses, pharmacists, opticians and dentists to provide centralised free point of service delivery to patients across the UK.

The principle behind this ambitious plan was borne out of the focus of ensuring that taxes collected from tax payers are utilised for this purpose, and access to the free service is not be based on how much of an income citizens earned, but more so on needs of patients. As time went on, demand for the service seem to be overburdened particularly on the basis of constrained financial resources to fund its continued existence. In order to continue with the focus of free service, a call was made in 1952 to levy 'One Shilling' charge for prescription on medication, but with some exemption for those who are not in active employment.

During the year 2000, NHS walk-in centres were introduced as a way of making it possible for everyone to access easy means of care without having to book prior appointments for services. In 2014, the NHS received special commendation from The Commonwealth Fund based on the 'Mirror, Mirror on the Wall, 2014 report' for high quality delivery and efficiency of services to patients care in comparison to countries like the USA where the service is considered very expensive in addressing the needs of the poor (The Commonwealth Fund, n/d).

\section{Economics of Cost-Saving Decisions in the Trust}

This is simply based on the economics of opportunity cost, which is to ensure that scarce resources are adequately rationalized in order that the focus of free health care is continually accessed by everyone in the country. In reality, the adoption of strict economic policy measures can prove very difficult and in most cases, authorities are seen as being unfair to society on account of hardline decisions to meet basic health care targets.

\subsection{Deciding Factor(s) of the Economics of Cost-saving}

As rightly noted by Seixas (2018: 346), economic efficiency seem more of the thinkable when it comes to prioritizing patients care in the NHS, which for a terminally / acutely ill patient, may be interpreted as inhumane. In its link to neoclassical economic thought as Seixas (ibid) rightly phrased it, economic efficiency in the NHS would normally encompass the following three factors:

1. Technical efficiency - this seeks to approach issues of efficiency on the basis of productivity of goods / services and this would involve the most possible explored means to achieve high level of outputs for a defined amount of input[s].

2. Cost-effectiveness efficiency is mostly determined by the least costly method of production, among defined technically efficient factors. 
3. Allocative efficiency - this is concerned with the distribution of goods in relation to their perceived judgment by individuals - this on a broader note, account for individual preferences, particularly in terms of their derived utility from goods or services.

While this is viewed as a priority to patient care, it also defeat the notion of free universal health care, which is highly needed for people and more so those considered to be acutely / terminally ill. In the discipline of health economics, such decision is perceived as a form of rationing of (public) economic good in a bid to ensuring that the focus of meeting free health care for all is achieved, but done in the wrong way to the detriment of curtailing life. Health economics according to Morris et al (2012), is the application of economic theory, models and empirical techniques to the analysis of decision-making by individuals, health care providers and governments with respect to health and health care. The principle of rationing service or delaying a suffering patient from accessing much needed care at the point of his / her distressed state is considered abusive to humanity, in a bid to rationalizing cost to meet targeted service provision.

In the production factor of health economics diagram shown in Figure 1 below, one may imagine the level of productivity that is ascribed to service provision to be based on the (efficient) allocation of scarce resources.

Figure 1: Health Economic Production Diagram

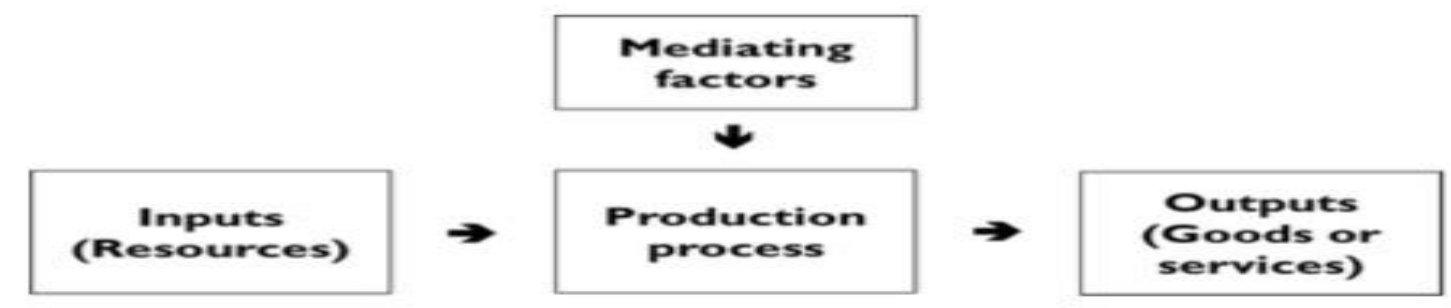

Source: Health Knowledge

In the context of resource rationing, even though sufficient input like health care professional support would have been addressed to ensure production process is efficiently utilized, there is also underlying question revolving around the satisfaction of service delivery to address patients' distressed state of pain / emotional well-being. This may be a discourse of critical debate in the area of professional reflection.

\subsection{Analysis of the Waiting List Optimisation}

NHS service is made accessible freely to all through government squeezed spending scheme to address thoughts around ensuring care provided for all can be construed 
critically. Figure 2 below addresses simple economic analysis of waiting list optimization where the demand for service is thought to be outstripping service provision and hence leaving patients in a scramble (lottery-like) system of waiting list, while continuing to struggle in silence on account of their agonized and emotional trauma.

\section{Figure 2: Representation for Demand and Supply of Health Care in the NHS}

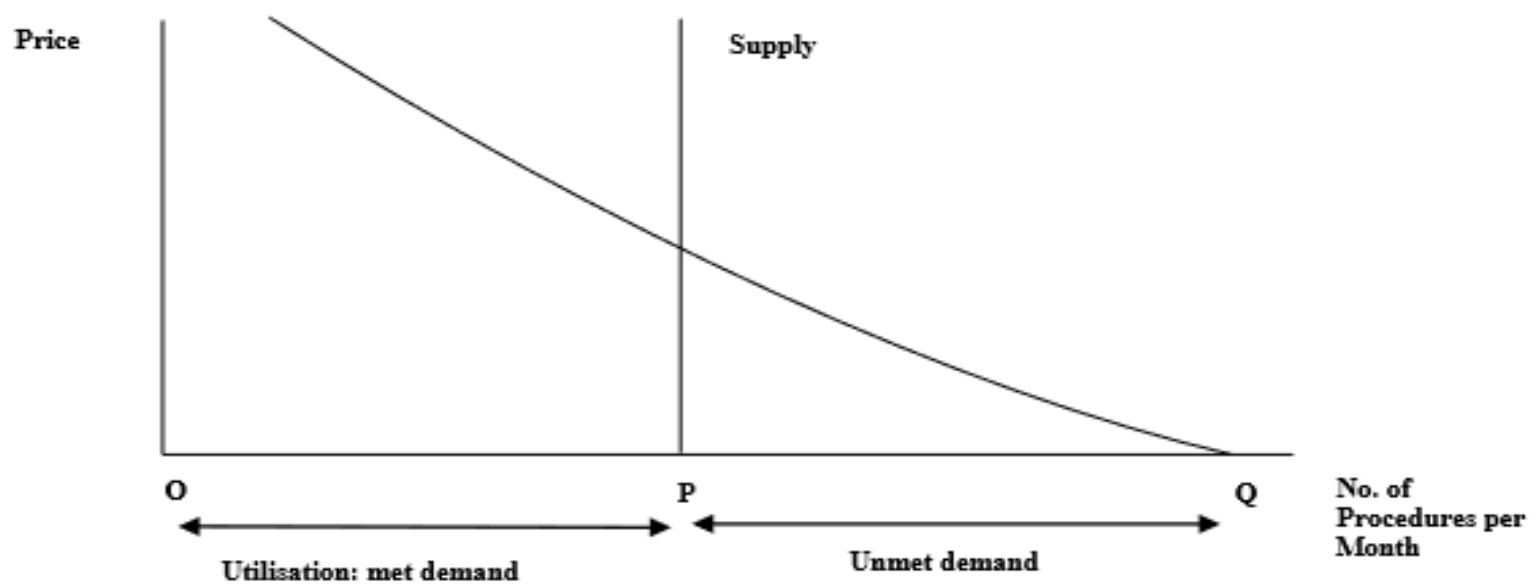

Source: Produced by Author (Adopted from Morris et al, 2012)

In view of Figure 2 above, Price is equal to 0 , which means effective demand will now be determined at point $Q$. The Supply curve which is set at point $P$ is vertical and due to the fact that there is no price reconciliation between demand and supply, particularly for a publicly accessible service like the NHS, there is an obvious unmet demand target determined at PQ as depicted in Figure 2. The utilization of service the system can accommodate is based on the availability of resources like medical personnel, hospital wards to accommodate patients, etc., as depicted by points OP. Therefore in this situation, the unmet demand for patient care in such a freely accessible system as defined by waiting time can prove very difficult in a situation of high level distress to much needed patients' medical condition(s). This then brings out serious concerns around ethics and morality, which is to be addressed critically under the next section heading.

\section{The Morality Discourse (Prioritisation of Patient Care)}

This section addresses morality framework around the prioritization of heath care services to patients in the NHS system. In all fairness, the NHS is serving its merited purpose of making do with scarce resources to care for millions of needy patients seemingly, a continuation of the original intention of the trust in ensuring free point of service is made available to all since its inception in the latter part of the 1940s. However, as demand for patient care grows, more so on account of rising population and increased cost of production, here comes a critical concern around moral issue of the rationalization of care when in most cases, a patient may be deprived of essential care to preserve life in distressed condition[s]. 


\subsection{Whose Health is of Priority?}

This is very important as far as ethics of morality is concerned in addressing patients care. It is an indisputable fact that budgets are being constrained on account of extended patient services provided more lately on free services provided (Morris et al, 2012). It is unbelievable sometimes to see that, in the midst of a dying being who has been diagnosed with almost a terminal disease, health professionals would be inclined to constrain essential service(s) to such a patient. One may be poised to throw question around concern for humanity in such critical situation, which is about the preservation of life, while to the decision makers, the focus is skewed towards the rationalization of a so-called constrained budget.

The most thriving and thought provoking point here surround concept on 'ethical prudence' of medical professionals who may feel very well convinced about their professional judgment(s), while a human being is psychologically tortured, even beyond his / her physiological well-being. The thought about denying an individual a service in a bid to meeting planned health care targets in a system like the NHS is beyond human comprehension. In times like this, a reflection on the Psalmist (46:1) passage which reads "God is our refuge and strength, always ready to help in times of trouble", may seem to be resounding in the minds of a dejected being who is considered religious (Biblia.com, $\mathrm{n} / \mathrm{d}$ ). On a similar note, to the non-religious being, the thought about dejection may be attributed differently, more likely to an extent of questioning the existence of God.

To the sufferer, the hermeneutics of such denial of well-being would simply be construed as been unfair (Jackson, 2016), while to that of the professional medics, it may be perceived as a saving cost venture, which is of no ethical prudence to the 'faint-hearted' or dying soul, who deserve no less of a decent and honored treatment. In such a situation, one may wonder as to whether health professionals are actually human beings.

\subsection{Argument for and Against Supportive Care}

When one takes a look at the area of moral economics, it is very important that the situation of immediate health need is factored when decisions are to be made about who is in need of urgent care. Personalized feelings of a patient is mostly 'swept underneath the carpet' by health professionals in their decision on who is considered as priority in a bid to prolong lives. In many cases, it may seem as if urgency around caring for a patient is only left at a critical point, when the patient may almost be at the point of dying, while 
health professionals are still convinced in their minds about the idea of a so-called resource rationalization.

The NHS England (2017: 3) study on "The Economics of Caring: A Scoping Review" addressed a rather important point which shows that the provision of effective health service will certainly improve patients' health status, and thus minimizing health and social care support provision - this is summarized as highlighted below:

- within the model, the mental health of the career is a pivotal mechanism. There are multiple suggested links (uni- and bi- directional) between this and their: physical health; ability to cope; ability to provide good quality care; and their use of health and social care services (positive effects assuming that caring responsibilities are not excessive). This suggests that improving careers' mental health would reap wider gains;

- the main economic benefits in this model (shown in the white box) derive from a reduction and / or delay in the career's use of health and social care services. It is not shown within the model, but this would also incorporate changes in the nature of service use - with a healthier / more able to cope career accessing services on a more planned basis than a career falling in and out of crisis. This would work differently for different 'types' of career: notably for young careers the ability to pursue education / training / employment would be the main benefit; and,

- there are very strong overlaps between this and Argument 3, which focuses more on benefits to the person with care need. This raises questions around the psychology of delayed decisions and the ethics to humanity.

This clearly shows the importance of holistic caring, which is based on timely assessment of patient needs as opposed to what is viewed as a cost saving venture to the NHS. Wrong decisions by management in the NHS can result in high costs to the trust, and this may ultimately result in high cost to intermediary support service(s) to patient, for example, psychological counselling to prevent emotional breakdown for those who may be experiencing some form of acute / terminal illness(es).

Amidst the emergent call for supportive care actions in the NHS, there is serious ethical concerns placed around people's perception of what is considered as supportive care or even an incident of the long suffering of humanity during their time in the world. The thought around opposing end of care treatment is one of political discourse where some may perceive it as an unnecessary waste of public funds aimed at prolonging the life span of those perceived to be critically / severely ill. The document on "Action for End of Life Care in England 2014 - 16" (2014) sets out the way of indirectly critiquing supportive care, while still holding the view that quality care is relevant for the existentiality of humanity, but not to the extent where poor standard of care is adding to the prolong suffering of the sufferer. 


\section{Psychological Torture of the Living Dead and Perceived Professional Gains}

In this section, the focus is to bring to the fore critical discourses on the economics of patient care, which is mostly about the rationalization of budgets, which eventually impact on lives, particularly in sustaining life of the living dead. The word "living dead" is used contextually here to address situational discomfort when it comes to addressing effective patients care.

\subsection{Impact on self, family members and friends}

The secret and anxiety of a long awaited result of a (near) acute / terminal illness is almost tantamount to physical torture, yet alone the decision from health professionals in concluding the fate of the living dead whose depressed state of mind is a resounding death in itself. Critically, it may almost sound patronizing when a patient diagnosed with terminal illness like cancer is told that 'you are rather young and hence, the professional gurus have decided that monitoring will be the best remedy to contain the situation'. In this situation, one may be absolutely right or wrong to say that such a professional is considered selfish and unethical - it is perceived that such judgments are normally done in a bid to maintaining the 'status quo' of meeting desired expenditure targets, while the outcome would almost be tantamount to killing distressed beings.

The impact of such decision(s) cannot be comprehended with, given the state of discomfort it places on family members and also friends / colleagues. As Morris et al (2012: 6) explain it, decision makers are not emotionally attached when it comes to dealing with decisions relating to whether a terminally ill patient should get a deserved (immediate) treatment, but rather based on the economics of opportunity cost. In this situation, the alternative of constraining budget to particular cases of illness is considered the most important and very little (if at all) to do with the impact of sad memories to those who would be left behind in the event that a patient is to die. Based on economic analysis of cost allocation, it is understandable about the need to ensure cost centers are allocated to address care needs, but when the decision is based only on selfish professional judgement, then the unthinkable feelings of humanity in a state of distress condition can be critically construed as morally unethical.

\subsection{Perceived Impacts on Provider of Service(s)}

Decision in the hands of health professionals about patient treatment is all based on the economics of rationing and most importantly, the notion of ensuring all patients are provided with the absolute basic free point of call treatment. With reference to Figure 2 above, it is seen that where demand for patient services outstrip supply of much needed resources, the ultimate focus is to rationalize resources such that the end goal is to create a system of (long) waiting list. 
Critical discourse would manifest that decision relating to which patient is to be prioritized is not based on a simple need of deserved and humane prudential consideration, but more so on the need to rationalize spending (Emmanuel and Emmanuel, 1994 and Lakdawalla et al, 2018). This may seem right as far as the application of economics of rationalization is concerned, but its moral dimension is seriously fraught with ethical issues, for example, the case of justifying to a patient that the reason for a prolong awaited care is due to him / her being considered young; the is based on the assumption that the patient may have long time to cope with the distress of a killer disease, while funds are solicited within an unknown time to deal with a serious health problem. In most cases, assumed prioritization of patients' care by medical professionals seem not to take cognizance of reputational risks to trusts or health care providers. This is indeed an area that needs addressing as the emotional pain of perceived unfair care provision continues to resonate in the minds of people throughout their lifetime.

\section{Conclusion and Where Else}

This article is based on critical heterodox viewpoint in assessing concept around the economics of health care service provision, particularly in the UK NHS; the attention here is focused in ensuring that the morality of decisions made by medical / health professionals are viewed from a balanced standpoint in deciphering the full implications of decision to patients, family members, friends and as well as on the reputation of the NHS.

From a moral standpoint, the capitalist market approach to determine who and when a patient should be considered for (deserved) treatment remains a point for critical discourse by both health professionals and the caring community on account of constrained health care resources. I suppose that the way forward on this unending discourse around the rationalization of resources in addressing patients care is to ensure professionals place themselves in the shoe of the distressed. While projected high cost in meeting treatments cannot be swept under the carpet, it is but wise for morality to be placed at the forefront of economic rationalization, in a bid to minimize distress to patients and also curtailing reputational risks to the NHS.

\section{References}

Biblia.com (n/d). Psalm 46:1. Available at: https://biblia.com/bible/nlt/Ps46.1. (Accessed: 2nd April, 2018).

Emmanuel, E.J and Emmanuel, L.L. (1994). The economics of dying--the illusion of cost savings at the end of life. New England Journal of medicine, Vol. 330(8): pp. 540-544.

Gilbert BJ, Clarke E, Leaver L. (2014). Morality and markets in the NHS. International Journal of Health Policy Management, Vol. 3(7): pp. 371-376. DOI: 10.15171/ijhpm.2014.123. 
Health Knowledge (n/d). Health Economics. Available at: https://www.healthknowledge.org.uk/public-health-textbook/medical-sociologypolicy-economics/4d-health-economics/principles.he. (Accessed: $4^{\text {th }}$ April, 2018).

Jackson, E.A. (2016). Phronesis and the Epistemological Journey through Research Undertakings involving Human Participants in the Context of Sierra Leone. Filosofia Theoretica: Journal of African Philosophy, Culture and Religions, Vol. 5(2): pp. 37-53. . DOI: $10.4314 / \mathrm{ft} . v 5 \mathrm{i} 2.3$.

Lakdawalla, D.N., Doshi, J.A., Garrison, L.P., Phelps, CE., Basu, A. and Danzon. P.M. (2018). Defining elements of value in health care - a health economics approach: an ISPOR Special Task Force report [3]. Value in Health, Vol. 21(2): pp. 131-139.

Masters, J. (2018). Donald Trump attacks the UK's health service, and Britain hits back. Available at: at: https://www.google.co.uk/amp/s/amp.cnn.com/cnn/2018/02/05/politics/trump-nhshealthcare-tweet/index.html. (Accessed: 3rd April, 2018).

Morris, S., Devlin, N., Parkin, D. and Spencer, A. (2012). Economic Analysis in Health Care (2nd Ed). United Kingdom: Wiley Publisher.

NHS Choices (n/d/). The History of the NHS in England. Available at: https: www.nhs.uk/NHSEngland/thenhs/nhshistory/Pages/NHShistory1948.aspx. (Accessed: $2^{\text {nd }}$ April, 2018).

NHS England (2014). NHS England's Actions for End of Life Care. Available at: https://www.england.nhs.uk/wp-content/uploads/2014/11/actions-eolc.pdf. Accessed: $19^{\text {th }}$ August, 2018.

NHS England (2017). "The Economics of Caring: A Scoping Review". The Strategy Unit and ICF, NHS Midlands and Lancashire Communication Support Unit.

Seixas BV. (2018). The no-destination ship of priority-setting in healthcare: a call for more democracy. International Journal of Health Policy Management. Vol. 7(4): pp. 345-348. DOI: 10.15171/ijhpm.2017.119.

The Commonwealth Fund. (n/d). Mirror, Mirror on the Wall, 2014 Update: How the U.Ss Health Care System Compares Internationally. Available at: https: www.commonwealthfund.org/publications/fund-reports/2014/jun/mirror-mirror. (Accessed: $1^{\text {st }}$ April, 2018). 